\title{
Hydrazinium Salt as Additive To Improve Film Morphology and Carrier Lifetime for High-Efficiency Planar-Heterojunction Perovskite Solar Cells via One-Step Method
}

Xin Zhang, ${ }^{\dagger}$ Sijian Yuan, ${ }^{\ddagger}$ Haizhou Lu, ${ }^{\ddagger \odot}$ Huotian Zhang, ${ }^{\ddagger}$ Pengfei Wang, ${ }^{\ddagger}$ Xiaolei Cui, ${ }^{\ddagger}$ Yin Zhang,

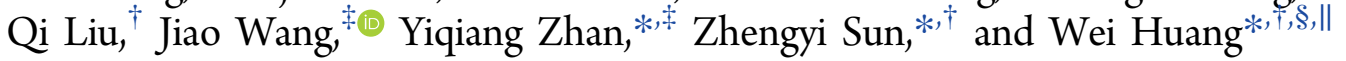

${ }^{\dagger}$ Key Laboratory of Flexible Electronics (KLOFE) \& Institute of Advanced Materials (IAM), Jiangsu National Synergistic Innovation Center for Advanced Materials (SICAM), Nanjing Tech University (NanjingTech), 30 South Puzhu Road, Nanjing 211800, China

${ }^{\ddagger}$ State Key Laboratory of ASIC and System, SIST, Fudan University, Shanghai 200433, China

${ }^{\S}$ Key Laboratory for Organic Electronics and Information Displays \& Institute of Advanced Materials (IAM), Jiangsu National Synergetic Innovation Center for Advanced Materials (SICAM), Nanjing University of Posts \& Telecommunications, 9 Wenyuan Road, Nanjing 210023, China

"Shaanxi Institute of Flexible Electronics (SIFE), Northwestern Polytechnical University (NPU), 127 West Youyi Road, Xi'an 710072, Shaanxi, China

\section{Supporting Information}

\begin{abstract}
One-step solution process is the simplest method to fabricate organic-inorganic metal halide perovskite thin films, which however does not work well when employed in the planar-heterojunction (PHJ) solar cells due to the generally poor film morphology. Here we show that hydrazinium chloride can be used as an additive in the precursor solution to produce perovskite films featuring higher coverage and better crystallinity. The light absorption ability and charge carrier lifetime are both significantly improved accordingly. Under the optimal additive ratio, the average power conversion efficiency (PCE) of the inverted $\mathrm{PHJ}$ perovskite solar cells greatly increases by as much as $70 \%$, and the champion device shows a satisfying PCE of $12.66 \%$. These results suggest that $\mathrm{N}_{2} \mathrm{H}_{5} \mathrm{Cl}$ is a promising additive for fabricating high-efficiency perovskite solar cells via one-step method, which could be of interest in the future commercial solar cell industry.
\end{abstract}

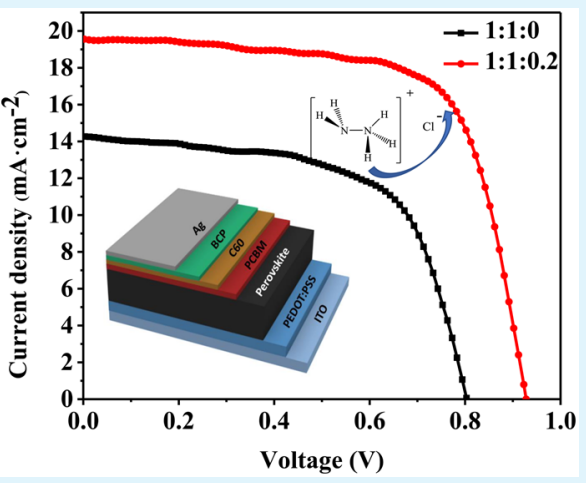

KEYWORDS: perovskite solar cells, inverted planar-heterojunction, hydrazinium salt, one-step method, morphology, carrier lifetime

\section{INTRODUCTION}

In the past few years, organic-inorganic metal halide perovskites have been demonstrated to be excellent materials in the fields of photovoltaics due to their simplicity of fabrication and outstanding photoelectrical properties, such as tunable band gaps, high absorption coefficients, high carrier mobility, long carrier lifetimes, and consequently, long diffusion lengths. ${ }^{1-5}$ Benefiting from these extraordinary features, the power conversion efficiency (PCE) of perovskite solar cells (PSCs) has been dramatically increased from an initial $3.8 \%{ }^{6}$ to $22.1 \%^{7}$ by now. Multifarious techniques to fabricate the perovskite thin film have been developed, including the onestep and two-step solution processes, the vapor-assisted solution process, coevaporation deposition, etc. ${ }^{8-14}$ Among these techniques, one-step method is the most widely used one, owing to its simplicity and cost efficiency, which are key factors for conducting large-scale production and realizing final commercialization. However, when the one-step method is employed to fabricate the PSCs with the planar-heterojunction $(\mathrm{PHJ})$ structure, the PCE is always undesirable (see Table S2 of the Supporting Information). The performance of PSCs significantly relies on the morphology of the perovskite film, especially for the PHJ-PSCs which does not have a mesoscopic structure to promote the contact between the absorbing layer and carrier collecting layer and to facilitate the crystal growth in the film. The perovskite crystals obtained by using one-step coating are normally needle-like, leading to an inhomogeneous and inconsecutive thin film with numerous large-sized pinholes $^{15}$ that causes a low conversion efficiency in the $\mathrm{PHJ}$ photovoltaic devices consequently.

Many efforts have been made to improve the quality of the one-step solution processed perovskite thin films, for instance, to begin with changing solvents and taking advantage of antisolvents. $^{16-20}$ However, the operation based on this strategy generally requires extremely precise control, which will increase the complexity of the preparation process.

Received: July 28, 2017

Accepted: October 6, 2017

Published: October 6, 2017 
(a)

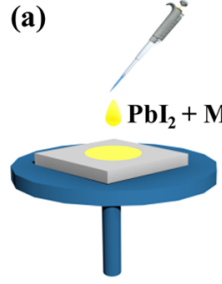

(b)

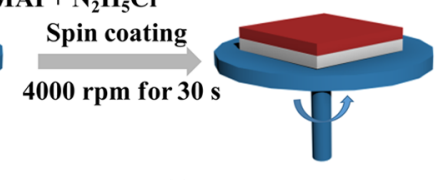

(c)

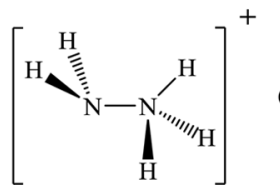

$1: 1: 0$

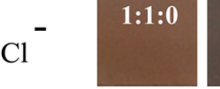

$1: 1: 0.1$

$1: 1: 0.2$

$1: 1: 0.3$

$1: 1: 0.4$

$1: 1: 0.5$

Figure 1. (a) Schematic diagram to illustrate the fabrication procedure. (b) Chemical structure of the hydrazinium chloride. (c) Color variation of the just-casted perovskite films fabricated without and with different ratios of $\mathrm{N}_{2} \mathrm{H}_{5} \mathrm{Cl}$ additive.

Introducing additives in the precursor solution has been demonstrated to be a simple and effective way to obtain highquality perovskite films. The addition of methylammonium acetate can help to generate highly uniform films with full coverage morphology and thio-semicarbazide is capable of increasing the crystal size. ${ }^{21}$ By selection of lead thiocyanate $\left(\mathrm{Pb}(\mathrm{SCN})_{2}\right)$ as additive and use of solvent annealing at the same time, the grain size can be increased effectively while averting the formation of excessive $\mathrm{PbI}_{2}{ }^{22}$ The introduction of acetonitrile into the $\mathrm{PbI}_{2} / N, N$-dimethylformamide (DMF) solution affects the bonding of $\mathrm{PbI}_{2}-\mathrm{DMF}$ complexes that can mediate the nucleation and grain growth pathway and form perovskite grains up to micrometer scale. ${ }^{23}$ A photochemically active additive benzoquinone induces a molecular interaction with methylammonium iodide $\left(\mathrm{CH}_{3} \mathrm{NH}_{3} \mathrm{I}, \mathrm{MAI}\right)$ in the precursor solution, which retards the formation of perovskite crystals and helps to obtain uniform and flat films with larger grains. ${ }^{24}$ In addition, a great number of chlorine salts as additive have been studied as well, including $\mathrm{HONH}_{3} \mathrm{Cl}, \mathrm{GuCl}, \mathrm{NaCl}$, and $\mathrm{CdCl}_{2},{ }^{25-29}$ which prove to be beneficial to the performance of corresponding devices. Overall, the strategy of taking advantage of additive is an extremely promising method to achieve high-efficiency PSCs.

Herein, hydrazinium chloride $\left(\mathrm{N}_{2} \mathrm{H}_{5} \mathrm{Cl}\right)$ is selected as an additive to tune the surface morphology and crystallinity of the perovskite films to improve the efficiency of PHJ-PSCs made by one-step solution process. By incorporation of $\mathrm{N}_{2} \mathrm{H}_{5} \mathrm{Cl}$ into the precursor solution of $\mathrm{PbI}_{2}$ and MAI at a 1:1 molar ratio dissolved in DMF solvent, enhanced film coverage and crystallinity were achieved. The resulting films possess better light absorption ability and longer carrier lifetime. The average PCE of the inverted PHJ devices using the optimal ratio of $\mathrm{N}_{2} \mathrm{H}_{5} \mathrm{Cl}$ to $\mathrm{PbI}_{2} / \mathrm{MAI}$ is significantly improved from the initial $6.70 \pm 0.44 \%$ to $11.41 \pm 0.64 \%$, and a champion device in our work shows the highest PCE of $12.66 \%$. We find that the $\mathrm{N}_{2} \mathrm{H}_{5} \mathrm{Cl}$ additive merely plays the role of facilitating the regular crystallization of $\mathrm{CH}_{3} \mathrm{NH}_{3} \mathrm{PbI}_{3}\left(\mathrm{MAPbI}_{3}\right)$ rather than doping the film.

\section{EXPERIMENTAL SECTION}

2.1. Materials and Device Fabrication. MAI (99.9\%) was purchased from Shanghai MaterWin New Materials Co., Ltd. $\mathrm{N}_{2} \mathrm{H}_{5} \mathrm{Cl}$ (98\%) was purchased from Energy Chemical. Other materials were purchased from Alfa Aesar or Sigma-Aldrich. All these materials were used as received without further purification. Indium tin oxide (ITO)coated glass substrates (10 $\Omega \mathrm{sq}^{-1}$, Shenzhen Nanbo Co.Ltd.) were ultrasonic-cleaned in detergent $(30 \mathrm{~min})$ and deionized water (15 $\mathrm{min})$ sequentially, and treated by UV-ozone $(10 \mathrm{~min})$ afterward. The poly(3,4-ethylenedioxythiophene) (PEDOT):polystyrenesulfonate (PSS) (CLEVIOS P VP Al 4083) layer was spin-coated on the cleaned ITO substrates in ambient at a speed of $5000 \mathrm{rpm}$ for $30 \mathrm{~s}$ and then annealed at $130{ }^{\circ} \mathrm{C}$ for $20 \mathrm{~min}$ in a vacuum-drying oven. The perovskite films were fabricated in a glovebox $\left(<0.1 \mathrm{ppm}\right.$ of $\mathrm{O}_{2}$ and $\mathrm{H}_{2} \mathrm{O}$ ). MAI and $\mathrm{PbI}_{2}$ were dissolved in DMF solvent at 1:1 molar ratio as the pristine precursor solution, and different molar ratios of $\mathrm{N}_{2} \mathrm{H}_{5} \mathrm{Cl}: \mathrm{PbI}_{2} / \mathrm{MAI}$ were added in. The prepared precursor solutions were sonicated for over $12 \mathrm{~h}$ in the dark and then spin-coated on PEDOT:PSS/ITO substrates at $4000 \mathrm{rpm}$ for $30 \mathrm{~s}$. After that, the films were annealed on a hot plate at $90{ }^{\circ} \mathrm{C}$ for $10 \mathrm{~min}$, as illustrated in Figure 1a. [6,6]-Phenyl- $\mathrm{C}_{61}$-butyric acid methyl ester (PCBM) was selected as the electron collection material, which was spin-coated on top of the perovskite layer at a speed of $2000 \mathrm{rpm}$ for $30 \mathrm{~s}$ from a solution in chlorobenzene $(20 \mathrm{mg} \mathrm{mL}-1)$. Finally, the device was completed by sequential thermal depositions of C60 $(20 \mathrm{~nm}), 2,9-$ dimethyl-4,7-diphenyl-1,10-phenanthroline (BCP, $8 \mathrm{~nm}$ ), and Ag (100 $\mathrm{nm}$ ) in an ultra-high-vacuum chamber integrated inside the glovebox, which formed an effective composite cathode.

2.2. Characterization. The crystal structures of the perovskite films were characterized by an X-ray diffractometer (Bruker-AXS D8). The scanning electron microscope (SEM) images of the film morphologies were obtained via a desktop SEM (Phenom Pro). The absorption spectra were measured using F20-UV thin-film analyzer (FILMETRICS) at wavelength range between 400 and $850 \mathrm{~nm}$. Timeresolved photoluminescence (PL) measurements were conducted by using Edinburgh LP920, a laser flash photolysis spectrometer operating at $532 \mathrm{~nm}$ with pulse duration of $7 \mathrm{~ns}$. Steady-state PL spectra were obtained by a homemade system, which used a MAL-E $514 \mathrm{~nm}$ laser as an excitation light source. The current-voltage $(J-V)$ curve and the incident photon-to-electron conversion efficiency (IPCE) were measured by a ZAHNER CIMPS electrochemical workstation (SF300-A, Sciencetech Inc., Canada) in a clean room (temperature, $25{ }^{\circ} \mathrm{C}$; relative humidity, 40\%) without device encapsulation, which was elaborated in detail in our previous work. ${ }^{30}$ The scanning direction for $J-V$ measurement was from negative bias to positive bias and the voltage scanning rate was $250 \mathrm{mV}$ $\mathrm{s}^{-1}$. In addition, we masked the solar cells with a three-dimensional printed epoxy resin aperture to define the active area $\left(0.06 \mathrm{~cm}^{2}\right)$. All these above-mentioned measurements were carried out in ambient air.

\section{RESULTS AND DISCUSSION}

Figure $1 \mathrm{~b}$ shows the chemical structure of $\mathrm{N}_{2} \mathrm{H}_{5} \mathrm{Cl}$ in which the position of the $\mathrm{CH}_{3}$ group was substituted by the similar-sized $\mathrm{NH}_{2}$ group when compared with the $\mathrm{CH}_{3} \mathrm{NH}_{3}{ }^{+}$ion. The perovskite films obtained from the precursor solutions $\left(\mathrm{PbI}_{2}\right.$ :MAI $\left.=1: 1\right)$ with $\mathrm{N}_{2} \mathrm{H}_{5} \mathrm{Cl}$ additive at different molar ratios $x$ ( $x$ varies from 0 to 0.5 with a 0.1 step) are hereafter 

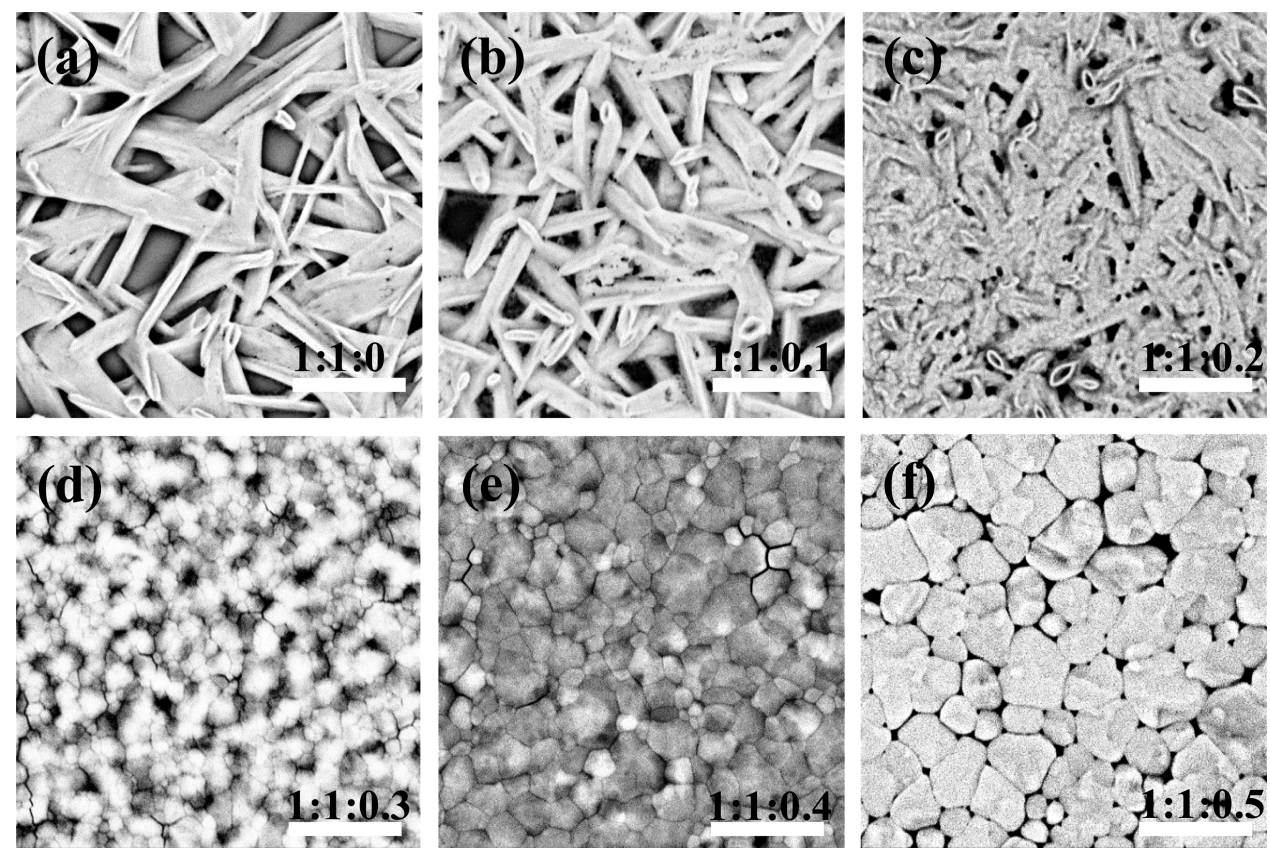

Figure 2. Top view SEM images of perovskite films obtained from the precursor solutions with $\mathrm{N}_{2} \mathrm{H}_{5} \mathrm{Cl}$ additive at different ratios to $\mathrm{PbI} / \mathrm{MAI}_{2}$ (a)-(f) refer to the pristine 1:1:0, 1:1:0.1, 1:1:0.2, 1:1:0.3, 1:1:0.4, and 1:1:0.5 films, respectively. The scale bar represents $5 \mu \mathrm{m}$.
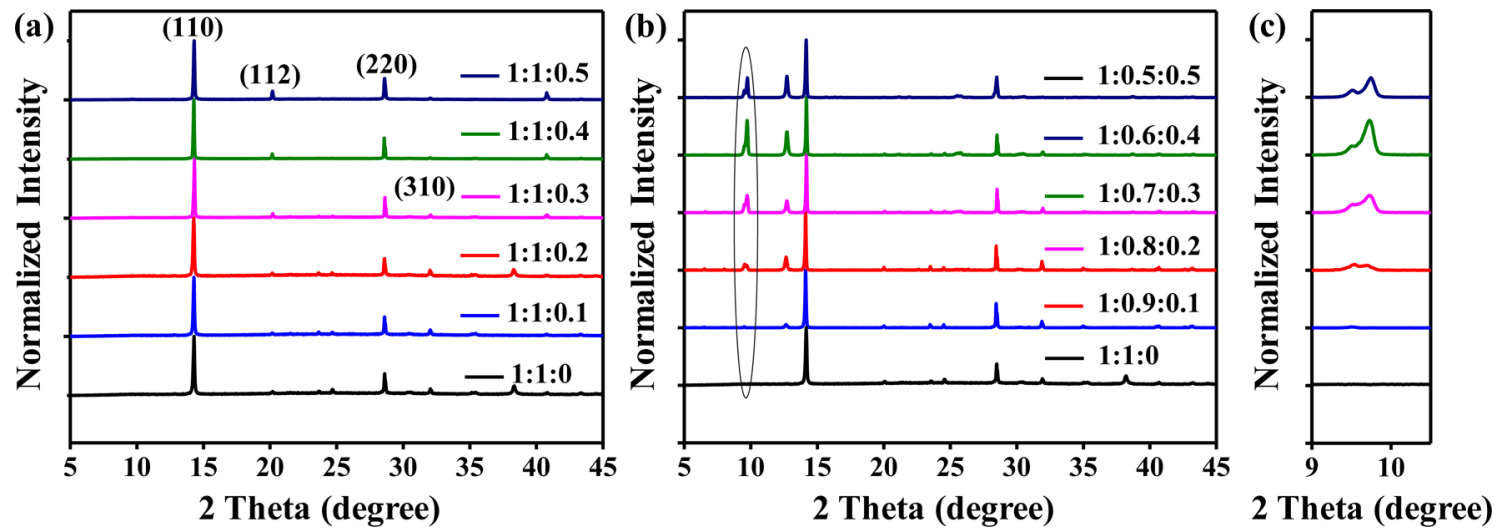

Figure 3. (a) XRD patterns of perovskite films fabricated from the precursor solutions of $\mathrm{PbI}_{2}: \mathrm{MAI}: \mathrm{N}_{2} \mathrm{H}_{5} \mathrm{Cl}=1: 1: x$. (b) XRD patterns of perovskite films fabricated from the precursor solutions of $\mathrm{PbI}_{2}: \mathrm{MAI}: \mathrm{N}_{2} \mathrm{H}_{5} \mathrm{Cl}=1:(1-x): x$. (c) Zoomed-in area of the circled range.

denoted as pristine 1:1:0, 1:1:0.1, 1:1:0.2, 1:1:0.3, 1:1:0.4, and 1:1:0.5 films. After spin-coating, the colors of the just-casted films are greatly changed with increasing $\mathrm{N}_{2} \mathrm{H}_{5} \mathrm{Cl}$ ratio, as shown in Figure 1c. The color of the pristine 1:1:0 film is just milky brown, while higher $\mathrm{N}_{2} \mathrm{H}_{5} \mathrm{Cl}$ ratios induce darker films and smoother surface. Apparently, the presence of the $\mathrm{N}_{2} \mathrm{H}_{5} \mathrm{Cl}$ additive can significantly facilitate the chemical reaction of precursors and accelerate the nucleation and growth of perovskite crystals during the spin-coating process.

The surface morphology of the resulting perovskite films was investigated by scanning electron microscopy (SEM). As shown in Figure 2, it is found that the pristine film has poor film quality with the acicular crystals forming a mesh structure, which results in a great number of large-sized pinholes and thus makes the film discontinuous. This is a very typical morphology for the perovskite film synthesized from the equimolar mixture of MAI and $\mathrm{PbI}_{2}$ in DMF solvent by one-step coating, as reported frequently in the literature. ${ }^{18,20,31-35}$ As a result, it can be expected that the light absorption ability will be impacted by the low surface coverage and the carrier recombination rate will be accelerated because of the direct contact between the hole collector and the electron collector via these pinholes. With increasing the amount of $\mathrm{N}_{2} \mathrm{H}_{5} \mathrm{Cl}$ additive, higher coverage can be achieved and the original acicular crystals gradually transform into the granular grains, as shown in Figure $2 b-d$. When the ratio of $\mathrm{N}_{2} \mathrm{H}_{5} \mathrm{Cl}: \mathrm{PbI}_{2} / \mathrm{MAI}$ is increased to 0.4, a consecutive film is obtained with grain size over $1 \mu \mathrm{m}$, but the crystals do not grow uniformly. Larger crystals can be obtained when the $\mathrm{N}_{2} \mathrm{H}_{5} \mathrm{Cl}$ ratio is increased to 0.5 , but a further increase of the $\mathrm{N}_{2} \mathrm{H}_{5} \mathrm{Cl}$ ratio leads to many pinholes again. Differing from the case of the pristine film, the pinholes here arise from the grain boundaries. From the SEM analysis, it is obvious that the surface morphology of perovskite film can be effectively tuned by the addition of $\mathrm{N}_{2} \mathrm{H}_{5} \mathrm{Cl}$ in the precursor solution. The $\mathrm{N}_{2} \mathrm{H}_{5} \mathrm{Cl}$ additive is inferred to influence the film morphology by restraining the formation of the acicular perovskite crystals and facilitating that of granular grain crystals.

$\mathrm{X}$-ray diffraction (XRD) analysis was conducted to investigate the impact of the $\mathrm{N}_{2} \mathrm{H}_{5} \mathrm{Cl}$ additive on the crystal structure of the perovskite film, as shown in Figure 3. In Figure 
3a, the dominant diffraction peaks of the pristine film are located at $14.1^{\circ}$ and $28.6^{\circ}$, corresponding to the (110) and (220) planes of the tetragonal structured perovskite, which is consistent with the previous literature. ${ }^{31}$ Intriguingly, with the increase of $\mathrm{N}_{2} \mathrm{H}_{5} \mathrm{Cl}$ ratio, the intensity of the peak at $20.1^{\circ}$ of the (112) plane is largely enhanced, implying that larger amounts of $\mathrm{N}_{2} \mathrm{H}_{5} \mathrm{Cl}$ would have an impact on the crystal orientation and further affect the device performance. ${ }^{36,37}$ In addition, the complete transformation of the precursor materials is confirmed by the absence of the characteristic peaks of $\mathrm{PbI}_{2}, \mathrm{MAI}$, and $\mathrm{N}_{2} \mathrm{H}_{5} \mathrm{Cl}$ in the resulting films (see Figure S1).

It is worth noting that the molar ratio of $\mathrm{PbI}_{2}: \mathrm{MAI}: \mathrm{N}_{2} \mathrm{H}_{5} \mathrm{Cl}$ in the above work is $1: 1: x$, so the total amount of MAI and $\mathrm{N}_{2} \mathrm{H}_{5} \mathrm{Cl}$ is larger than that of $\mathrm{PbI}_{2}$. The result indicates that the excess part of precursors, either MAI or $\mathrm{N}_{2} \mathrm{H}_{5} \mathrm{Cl}$, sublimates during the film annealing. To further understand the reaction process, we partially substitute $\mathrm{N}_{2} \mathrm{H}_{5} \mathrm{Cl}$ for MAI to keep their total number of moles equal to that of $\mathrm{PbI}_{2}$. The ratios of precursor materials were changed to $1:(1-x): x$, where $x$ also varies from 0 to 0.5 in steps of 0.1 (i.e., $\mathrm{PbI}_{2}: \mathrm{MAI}: \mathrm{N}_{2} \mathrm{H}_{5} \mathrm{Cl}=$ $1: 1: 0,1: 0.9: 0.1,1: 0.8: 0.2,1: 0.7: 0.3,1: 0.6: 0.4$, and 1:0.5:0.5, respectively). As shown in Figure $3 \mathrm{~b}$, a new peak located at $12.8^{\circ}$, which is assigned to the characteristic peak of $\mathrm{PbI}_{2}$, can be observed and the intensity was gradually enhanced with an increasing $\mathrm{N}_{2} \mathrm{H}_{5} \mathrm{Cl}$ ratio. Moreover, there is an extra dual peak emerging at approximately $10^{\circ}$ as shown in Figure $3 \mathrm{c}$, which is inferred to belong to the intermediate products during the fabrication process. These results show that the equivalent substitute of $\mathrm{N}_{2} \mathrm{H}_{5} \mathrm{Cl}$ for MAI will lead to the residue of $\mathrm{PbI}_{2}$, implying $\mathrm{N}_{2} \mathrm{H}_{5} \mathrm{Cl}$ cannot partially replace MAI to form the stable perovskite structure with $\mathrm{PbI}_{2}$. Therefore, the $\mathrm{N}_{2} \mathrm{H}_{5} \mathrm{Cl}$ additive is more likely to solely influence the crystallization process of the $\mathrm{MAPbI}_{3}$ film rather than acting as a dopant.

The UV-visible absorption spectra reflect the impact of the $\mathrm{N}_{2} \mathrm{H}_{5} \mathrm{Cl}$ additive on the optical properties of $\mathrm{MAPbI}_{3}$ films, as shown in Figure 4. Apparently, the pristine 1:1:0 film exhibits a

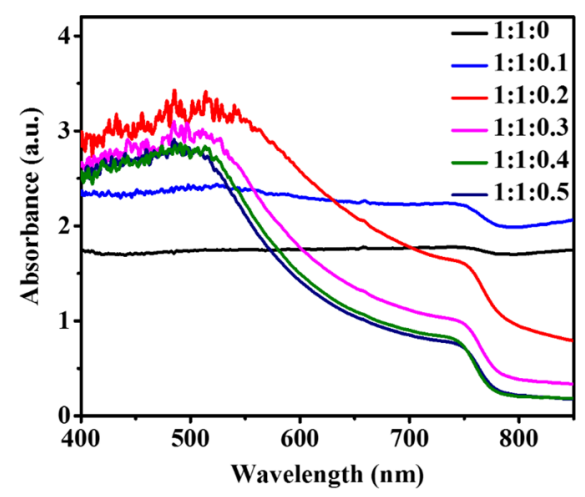

Figure 4. UV-visible absorption spectra of the perovskite films from the precursor solutions of $\mathrm{PbI}_{2}: \mathrm{MAI}: \mathrm{N}_{2} \mathrm{H}_{5} \mathrm{Cl}=1: 1: x$.

relatively flat absorption curve over the UV-vis region due to the low nucleation and incomplete surface coverage which have been shown earlier, and this result is consistent with the previous report. ${ }^{32}$ When the ratio of $\mathrm{N}_{2} \mathrm{H}_{5} \mathrm{Cl}$ is increased to 0.1, the scale and quantity of pores become smaller, causing a slightly stronger absorbance. It should be noted that the curve shape is similar to that of the pristine film because the 1:1:0.1 film still consists of needle-like crystals, as shown in Figure $2 \mathrm{~b}$. When the ratios of $\mathrm{N}_{2} \mathrm{H}_{5} \mathrm{Cl}$ range between 0.2 and 0.5 , the absorbance of the perovskite films is significantly improved with an onset at approximately $780 \mathrm{~nm}$. Particularly, 1:1:0.2 film possesses the highest absorbance. However, a higher $\mathrm{N}_{2} \mathrm{H}_{5} \mathrm{Cl}$ ratio results in the decreased light absorption again, which is consistent with the variation trend of the morphology in the SEM results. The improvement of absorbance is mainly attributed to the increased film coverage and the better morphology that lead to higher light-harvesting efficiency. ${ }^{38}$

The effect of the $\mathrm{N}_{2} \mathrm{H}_{5} \mathrm{Cl}$ additive on the photovoltaic performance of the $\mathrm{PHJ}-\mathrm{PSC}$ was investigated by utilizing the inverted structure of ITO/PEDOT:PSS $/ \mathrm{MAPbI}_{3} / \mathrm{PCBM} /$ $\mathrm{C} 60 / \mathrm{BCP} / \mathrm{Ag}$, as shown in Figure $5 \mathrm{a}$. Figure $5 \mathrm{~b}$ provides the corresponding energy level diagram. For clear illustration of the relationship between device performance and the ratio of $\mathrm{N}_{2} \mathrm{H}_{5} \mathrm{Cl}$, the average PCEs of different devices are collectively shown in Figure 5c. All the detailed photovoltaic parameters, including the average value and the optimum value, can be found in Table S1. As standard control samples, the average performance of the pristine 1:1:0 device exhibits an open-circuit voltage $\left(V_{\text {oc }}\right)$ of $0.81 \mathrm{~V}$, a short-circuit current density $\left(J_{\text {sc }}\right)$ of $13.58 \mathrm{~mA} \cdot \mathrm{cm}^{-2}$, and a fill factor (FF) of 0.61 , yielding a relatively low PCE of $6.70 \%$. The PCEs of the PSCs using the same structure and fabrication process reported in the literature are summarized in Table S2, from which it can be seen that the low PCE is a very general result. With the addition of $\mathrm{N}_{2} \mathrm{H}_{5} \mathrm{Cl}$, all of the $V_{\mathrm{oO}} J_{\mathrm{sc}}$ and $\mathrm{FF}$ values have significant improvements. When the ratio of $\mathrm{N}_{2} \mathrm{H}_{5} \mathrm{Cl}$ is 0.1 , these performance parameters turn into $0.88 \mathrm{~V}, 16.41 \mathrm{~mA} \cdot \mathrm{cm}^{-2}$, and 0.65 , increasing by $8.6 \%$, $20.8 \%$, and $6.5 \%$, respectively. The resulting PCE is $9.45 \%$, which realizes a tremendous improvement by $41.0 \%$. As the ratio of $\mathrm{N}_{2} \mathrm{H}_{5} \mathrm{Cl}$ keeps increasing, the 1:1:0.2 device achieves the best performance in our work, with the average $V_{\mathrm{oc}} J_{\mathrm{sc}}$ and FF of $0.92 \mathrm{~V}, 18.62 \mathrm{~mA} \cdot \mathrm{cm}^{-2}$, and 0.67 , respectively. The average PCE reaches $11.41 \%$, which is up to $70.3 \%$ higher than the one of the pristine device. However, when the additive ratio continues to increase, the PCE of the device starts to decrease due to the reduction of $J_{\mathrm{sc}}$ and FF, which may originate from the decreased light absorption and the growing number of grain boundaries in the film. For a clearer comparison, we provide the $J-V$ curves of the optimum pristine device and the optimum 1:1:0.2 device in Figure 5d. Thanks to the remarkable enhancement of all $V_{\mathrm{oc}} J_{\mathrm{sc}}$ and FF values, the highest PCE obtained by a $1: 1: 0.2$ device is up to $12.66 \%$, which increases by $72.7 \%$ compared with that of the best pristine 1:1:0 device of $7.33 \%$. The corresponding IPCE spectra are presented in Figure 5e. The 1:1:0.2 device shows a much higher IPCE plateau (>70\%) between 425 and $725 \mathrm{~nm}$ than the pristine device. The $J_{s c}$ values integrated from the IPCE are 19.6 and $14.8 \mathrm{~mA} \cdot \mathrm{cm}^{-2}$ for $1: 1: 0.2$ and pristine devices, respectively, which agree well with those in the $J-V$ measurements shown in Figure 5d.

To better understand the enhancement effect of the $\mathrm{N}_{2} \mathrm{H}_{5} \mathrm{Cl}$ additive on the device performance, we compared the steadystate and time-resolved PL spectra of the corresponding perovskite films. Both steady-state PL peaks of the films on PEDOT:PSS/ITO substrates are located in the region of $760 \sim 780 \mathrm{~nm}$, which is in accordance with the bandgap of $\mathrm{MAPbI}_{3}$ and the UV-visible absorption spectrum (Figure 4). However, for the 1:1:0.2 $\mathrm{MAPbI}_{3}$ film, the normalized spectrum shows a blue shift by $8 \mathrm{~nm}$ (from 778 to $770 \mathrm{~nm}$ ), as shown in Figure 6a, along with the full width at halfmaximum (fwhm) shrinking from 39 to $35 \mathrm{~nm}$. The blue shift of the PL peak echoes the relatively narrow fwhm, together 
(a)

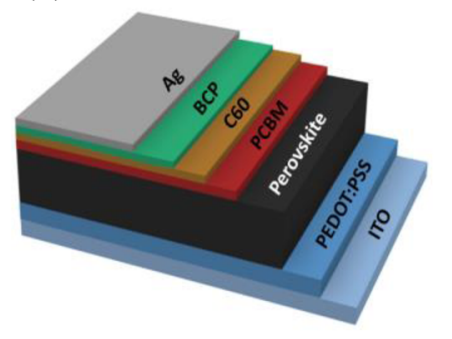

(b)

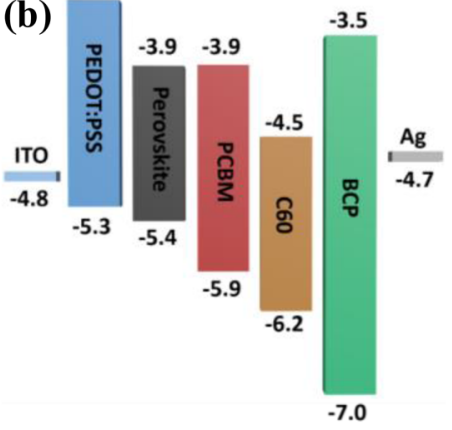

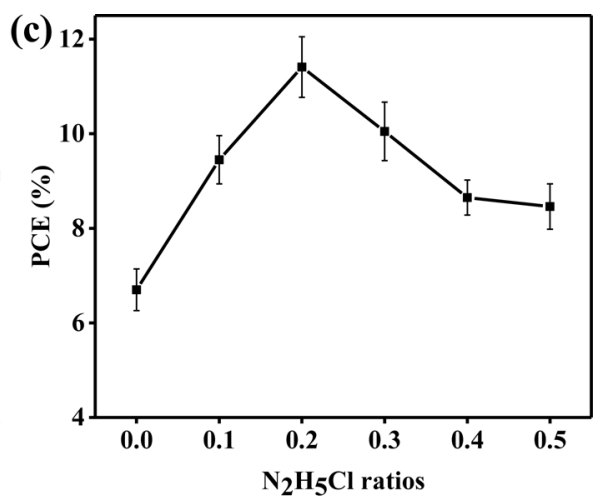
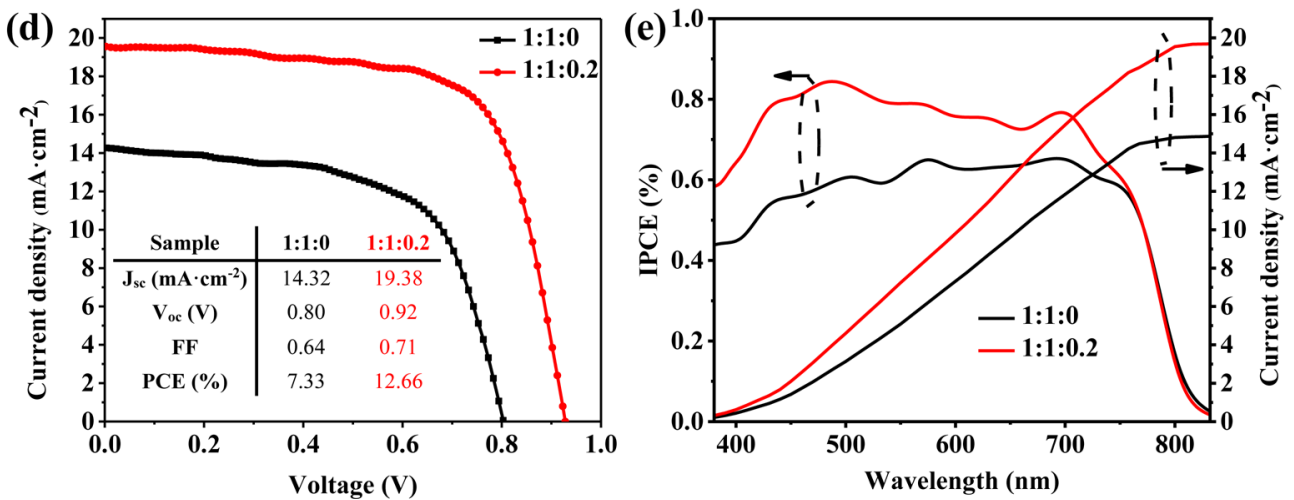

Figure 5. (a) Device architecture and (b) the energy level diagram of the PSCs. (c) PCEs of the devices plotted as a function of $\mathrm{N}_{2} \mathrm{H}_{5} \mathrm{Cl}$ ratios. (d) $J-V$ curves, (e) IPCE, and integrated $J_{\mathrm{sc}}$ of the best 1:1:0.2 device and the pristine counterpart.
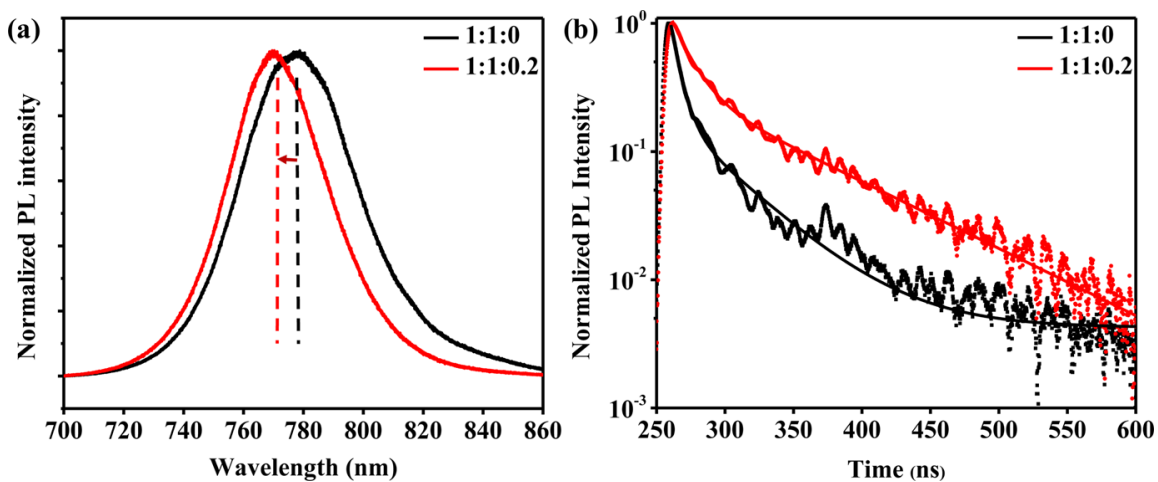

Figure 6. (a) Normalized steady-state PL spectra and (b) time-resolved PL spectra of pristine and 1:1:0.2 $\mathrm{MAPbI}_{3}$ films.

indicating a suppressed spontaneous radiative recombination and a lower trap density, which is probably the origin of the enhanced $V_{\text {oc }}{ }^{39}$ Time-resolved PL measurements were conducted on the films deposited on a glass substrate, and the results are presented in Figure $6 \mathrm{~b}$, in which all spectra are fitted with a double exponential decay equation and yield two types of lifetimes, the fast decay time $\tau_{1}$ and the slow decay time $\tau_{2}{ }^{40}$ It should be noted that these two different decay times can be assigned to the surface and bulk properties, respectively. ${ }^{2}$ As a result, the lifetime of 1:1:0.2 $\mathrm{MAPbI}_{3}$ film $\left(\tau_{1}=13.64 \mathrm{~ns}, \tau_{2}=\right.$ $80.82 \mathrm{~ns}$ ) shows largely improved $\tau_{1}$ and $\tau_{2}$ compared to those of the pristine film $\left(\tau_{1}=7.26 \mathrm{~ns}, \tau_{2}=50.91 \mathrm{~ns}\right)$. Our study reveals that, with the incorporation of the $\mathrm{N}_{2} \mathrm{H}_{5} \mathrm{Cl}$ additive in the perovskite film fabrication, the charge carrier lifetime is significantly enhanced, which plays an important role in the improvement of device efficiency.
It is also reasonable to associate the optimal photovoltaic performance with the unique morphology of 1:1:0.2 perovskite film. From the SEM images in Figure 2, it is obvious that, with an increasing amount of $\mathrm{N}_{2} \mathrm{H}_{5} \mathrm{Cl}$, the acicular perovskite crystals are tapering off while the large-sized granular crystals are formed. Apparently, although the pinholes are eliminated, a number of grain boundaries are generated. The grain boundaries negatively affect the device performance, especially $J_{\text {sc }}$, due to the boundary-induced high resistance and recombination center across the film. This is consistent with the $J_{\text {sc }}$ variation shown in Table $S 1$. Therefore, with the increased amount of $\mathrm{N}_{2} \mathrm{H}_{5} \mathrm{Cl}$, pinhole numbers are reduced, whereas grain boundary numbers are increased. As a result, there should be an optimal morphology, corresponding to an ideal ratio of $\mathrm{N}_{2} \mathrm{H}_{5} \mathrm{Cl}$ additive that is found to be 0.2 in our work. In this case, as shown in Figure $2 c$, most of the pinholes have disappeared but the majority of crystals are still of needle- 
like character rather than granular; that is, very few grain boundaries exist. The crystal film is in a kind of mixture or intermediate state, which shows the best properties for actual device application.

Furthermore, the reproducibility of the pristine and 1:1:0.2 PSCs was characterized by analyzing more than 20 individual devices. The statistical histogram of the PCEs is shown in Figure 7. By comparison, devices made from the 1:1:0.2 films

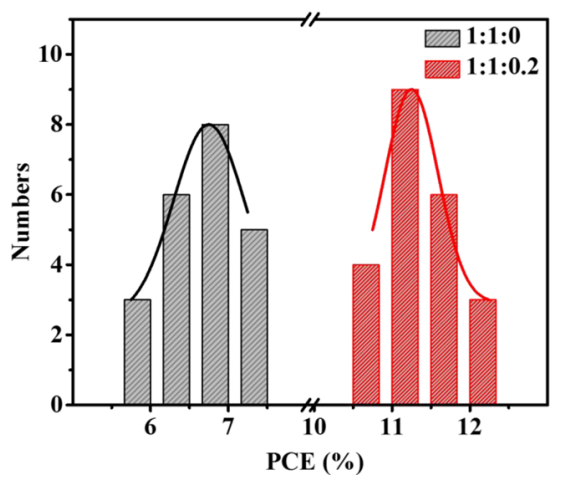

Figure 7. PCE distribution histogram of PSCs based on the pristine and 1:1:0.2 $\mathrm{MAPbI}_{3}$ films.

yield an average PCE which is approximately twice as high as that of the pristine devices. Meanwhile, the reproducibility of devices with PCEs over $11.0 \%$ is excellent. Since many studies as to additive engineering have been reported by now, in the end, we collect a group of halide additives for the comparison, as shown in Table S3. The devices employing the mesoporous structure incline to possess higher PCEs than the PHJ devices, indicating that achieving a competitively high efficiency requires the combination of both additive and suitable device architecture. Multiple-additives mixture is also developed to make the extremely high efficiency PSCs, even based on PHJ structure. Thus, it can be expected that the $\mathrm{N}_{2} \mathrm{H}_{5} \mathrm{Cl}$ additive has the potential to make a higher performance device along with the optimized precursor solution and device structure.

\section{CONCLUSIONS}

In summary, we have demonstrated that $\mathrm{N}_{2} \mathrm{H}_{5} \mathrm{Cl}$ can be used as an effective precursor additive to tune the crystallization and morphology of perovskite films in one-step method. The introduction of $\mathrm{N}_{2} \mathrm{H}_{5} \mathrm{Cl}$ helps the film to achieve higher coverage and crystallinity. As a result, the light absorption ability (optical property) and charge carrier lifetime (electrical property) have been significantly improved. When the ratio of $\mathrm{N}_{2} \mathrm{H}_{5} \mathrm{Cl}$ is 0.2 , the film consists of both needle-like crystals and granular grains, which on the one hand leads to much fewer pinholes compared with the pristine counterpart, while on the other hand leads to less grain boundaries of the crystals compared with the higher-additive-ratio counterparts. Inverted PHJ-PSCs based on the 1:1:0.2 films show an average PCE of $11.41 \%$, with the best one being $12.66 \%$, which prove the potential of $\mathrm{N}_{2} \mathrm{H}_{5} \mathrm{Cl}$ and extend the additive selection for the high-efficiency $\mathrm{PHJ}-\mathrm{PSCs}$ fabricated by the simple one-step method.

\section{ASSOCIATED CONTENT}

\section{S Supporting Information}

The Supporting Information is available free of charge on the ACS Publications website at DOI: 10.1021/acsami.7b11168.
XRD patterns of the $\mathrm{N}_{2} \mathrm{H}_{5} \mathrm{Cl}, \mathrm{PbI}_{2}, \mathrm{MAI}$, the pristine, and 1:1:0.2 perovskite films (Figure $\mathrm{S} 1$ ); performance parameters of the PSCs fabricated with $\mathrm{N}_{2} \mathrm{H}_{5} \mathrm{Cl}$ additive at different ratios (Table S1); PCEs of the inverted PHJPSCs fabricated by the "conventional" one-step method reported in the literature (Table S2); effects of the halide additives on the performance of the PSCs with kinds of device architectures (Table S3) (PDF)

\section{AUTHOR INFORMATION}

\section{Corresponding Authors}

*E-mail: yqzhan@fudan.edu.cn (Y.Z.).

*E-mail: iamzysun@njtech.edu.cn (Z.S.).

*E-mail: wei-huang@njtech.edu.cn (W.H.).

ORCID

Xin Zhang: 0000-0002-2228-3633

Haizhou Lu: 0000-0001-9692-7860

Huotian Zhang: 0000-0002-9302-4129

Jiao Wang: 0000-0001-7640-3947

Notes

The authors declare no competing financial interest.

\section{ACKNOWLEDGMENTS}

This work was financially supported by the National Basic Research Program of China-Fundamental Studies of Perovskite Solar Cells (2015CB932200) and National Natural Science Foundation of China (11504168). Part of this work was also supported by the Natural Science Foundation of Shanghai (17ZR1402100) and The National Key Research and Development Program of China (2016YFE0110700). We are grateful to Dr. M. Meissner from the Institute for Molecular Science for his kind and helpful discussion.

\section{REFERENCES}

(1) Baikie, T.; Fang, Y.; Kadro, J. M.; Schreyer, M.; Wei, F.; Mhaisalkar, S. G.; Gratzel, M.; White, T. J. Synthesis and Crystal Chemistry of the Hybrid Perovskite $\left(\mathrm{CH}_{3} \mathrm{NH}_{3}\right) \mathrm{PbI}_{3}$ for Solid-State Sensitised Solar Cell Applications. J. Mater. Chem. A 2013, 1, 56285641.

(2) Dong, Q.; Fang, Y.; Shao, Y.; Mulligan, P.; Qiu, J.; Cao, L.; Huang, J. Electron-Hole Diffusion Lengths $>175 \mu \mathrm{m}$ in SolutionGrown $\mathrm{CH}_{3} \mathrm{NH}_{3} \mathrm{PbI}_{3}$ Single Crystals. Science 2015, 347, 967-970.

(3) Li, Y.; Yan, W.; Li, Y.; Wang, S.; Wang, W.; Bian, Z.; Xiao, L.; Gong, Q. Direct Observation of Long Electron-Hole Diffusion Distance in $\mathrm{CH}_{3} \mathrm{NH}_{3} \mathrm{PbI}_{3}$ Perovskite Thin Film. Sci. Rep. 2015, 5, 14485.

(4) Ponseca, C. S., Jr; Savenije, T. J.; Abdellah, M.; Zheng, K.; Yartsev, A.; Pascher, T.; Harlang, T.; Chabera, P.; Pullerits, T.; Stepanov, A.; Wolf, J.-P.; Sundström, V. Organometal Halide Perovskite Solar Cell Materials Rationalized: Ultrafast Charge Generation, High and Microsecond-Long Balanced Mobilities, and Slow Recombination. J. Am. Chem. Soc. 2014, 136, 5189-5192.

(5) Wang, D.-L.; Cui, H.-J.; Hou, G.-J.; Zhu, Z.-G.; Yan, Q.-B.; Su, G. Highly Efficient Light Management for Perovskite Solar Cells. Sci. Rep. 2016, 6, 18922.

(6) Kojima, A.; Teshima, K.; Shirai, Y.; Miyasaka, T. Organometal Halide Perovskites as Visible-Light Sensitizers for Photovoltaic Cells. J. Am. Chem. Soc. 2009, 131, 6050-6051.

(7) Yang, W. S.; Park, B.-W; Jung, E. H.; Jeon, N. J.; Kim, Y. C.; Lee, D. U.; Shin, S. S.; Seo, J.; Kim, E. K.; Noh, J. H.; Seok, S. I. Iodide Management in Formamidinium-Lead-Halide-Based Perovskite Layers for Efficient Solar Cells. Science 2017, 356, 1376-1379.

(8) Bai, S.; Sakai, N.; Zhang, W.; Wang, Z.; Wang, J. T.-W.; Gao, F.; Snaith, H. J. Reproducible Planar Heterojunction Solar Cells Based on 
One-Step Solution-Processed Methylammonium Lead Halide Perovskites. Chem. Mater. 2017, 29, 462-473.

(9) Burschka, J.; Pellet, N.; Moon, S.-J.; Humphry-Baker, R.; Gao, P.; Nazeeruddin, M. K.; Grätzel, M. Sequential Deposition as a Route to High-Performance Perovskite-Sensitized Solar Cells. Nature 2013, 499, 316-320.

(10) Chen, Q.; Zhou, H.; Hong, Z.; Luo, S.; Duan, H.-S.; Wang, H.H.; Liu, Y.; Li, G.; Yang, Y. Planar Heterojunction Perovskite Solar Cells via Vapor-Assisted Solution Process. J. Am. Chem. Soc. 2014, 136, 622-625.

(11) EL-Henawey, M. I.; Gebhardt, R.; El-Tonsy, M. M.; Chaudhary, S. Organic Solvent Vapor Treatment of the Lead Iodide Layer in the Two-Step Sequential Deposition of $\mathrm{CH}_{3} \mathrm{NH}_{3} \mathrm{PbI}_{3}$-Based Perovskite Solar Cells. J. Mater. Chem. A 2016, 4, 1947-1952.

(12) Liu, M.; Johnston, M. B.; Snaith, H. J. Efficient Planar Heterojunction Perovskite Solar Cells by Vapour Deposition. Nature 2013, 501, 395-398.

(13) Xiao, Z.; Bi, C.; Shao, Y.; Dong, Q.; Wang, Q.; Yuan, Y.; Wang, C.; Gao, Y.; Huang, J. Efficient, High Yield Perovskite Photovoltaic Devices Grown by Interdiffusion of Solution-Processed Precursor Stacking Layers. Energy Environ. Sci. 2014, 7, 2619-2623.

(14) Zhang, W.; Saliba, M.; Moore, D. T.; Pathak, S. K.; Horantner, M. T.; Stergiopoulos, T.; Stranks, S. D.; Eperon, G. E.; AlexanderWebber, J. A.; Abate, A.; Sadhanala, A.; Yao, S.; Chen, Y.; Friend, R. H.; Estroff, L. A.; Wiesner, U.; Snaith, H. J. Ultrasmooth OrganicInorganic Perovskite Thin-Film Formation and Crystallization for Efficient Planar Heterojunction Solar Cells. Nat. Commun. 2015, 6, 6142.

(15) Kang, R.; Kim, J.-E.; Yeo, J.-S.; Lee, S.; Jeon, Y.; Kim, D.-Y. Optimized Organometal Halide Perovskite Planar Hybrid Solar Cells via Control of Solvent Evaporation Rate. J. Phys. Chem. C 2014, 118, 26513-26520.

(16) Jeon, N. J.; Noh, J. H.; Kim, Y. C.; Yang, W. S.; Ryu, S.; Seok, S. Il. Solvent Engineering for High-Performance Inorganic-organic Hybrid Perovskite Solar Cells. Nat. Mater. 2014, 13, 897-903.

(17) Jung, J. W.; Williams, S. T.; Jen, A. K. Y. Low-Temperature Processed High-Performance Flexible Perovskite Solar Cells via Rationally Optimized Solvent Washing Treatments. RSC Adv. 2014, 4, 62971-62977.

(18) Paek, S.; Cho, N.; Choi, H.; Jeong, H.; Lim, J. S.; Hwang, J.-Y.; Lee, J. K.; Ko, J. Improved External Quantum Efficiency from Solution-Processed $\left(\mathrm{CH}_{3} \mathrm{NH}_{3}\right) \mathrm{PbI}_{3}$ Perovskite $/ \mathrm{PC}_{71} \mathrm{BM}$ Planar Heterojunction for High Efficiency Hybrid Solar Cells. J. Phys. Chem. C 2014, 118, 25899-25905.

(19) Fang, X.; Wu, Y.; Lu, Y.; Sun, Y.; Zhang, S.; Zhang, J.; Zhang, W.-H.; Yuan, N.-Y.; Ding, J. Annealing-Free Perovskite Films Based on Solvent Engineering for Efficient Solar Cells. J. Mater. Chem. C 2017, $5,842-847$

(20) Xiao, M.; Huang, F.; Huang, W.; Dkhissi, Y.; Zhu, Y.; Etheridge, J.; Gray-Weale, A.; Bach, U.; Cheng, Y.-B.; Spiccia, L. A Fast Deposition-Crystallization Procedure for Highly Efficient Lead Iodide Perovskite Thin-Film Solar Cells. Angew. Chem. 2014, 126, 1005610061.

(21) Wu, Y.; Xie, F.; Chen, H.; Yang, X.; Su, H.; Cai, M.; Zhou, Z.; Noda, T.; Han, L. Thermally Stable $\mathrm{MAPbI}_{3}$ Perovskite Solar Cells with Efficiency of $19.19 \%$ and Area over $1 \mathrm{~cm}^{2}$ Achieved by Additive Engineering. Adv. Mater. 2017, 29, 1701073.

(22) Yu, Y.; Wang, C.; Grice, C. R.; Shrestha, N.; Zhao, D.; Liao, W.; Guan, L.; Awni, R. A.; Meng, W.; Cimaroli, A. J.; Zhu, K.; Ellingson, R. J.; Yan, Y. Synergistic Effects of Lead Thiocyanate Additive and Solvent Annealing on the Performance of Wide-Bandgap Perovskite Solar Cells. ACS Energy Lett. 2017, 2, 1177-1182.

(23) Li, L.; Chen, Y.; Liu, Z.; Chen, Q.; Wang, X.; Zhou, H. The Additive Coordination Effect on Hybrids Perovskite Crystallization and High-Performance Solar Cell. Adv. Mater. 2016, 28, 9862-9868.

(24) Qin, C.; Matsushima, T.; Fujihara, T.; Adachi, C. Multifunctional Benzoquinone Additive for Efficient and Stable Planar Perovskite Solar Cells. Adv. Mater. 2017, 29, 1603808.
(25) Dong, G.; Ye, T.; Pang, B.; Yang, Y.; Sheng, L.; Shi, Y.; Fan, R.; Wei, L.; Su, T. $\mathrm{HONH}_{3} \mathrm{Cl}$ Optimized $\mathrm{CH}_{3} \mathrm{NH}_{3} \mathrm{PbI}_{3}$ Films for Improving Performance of Planar Heterojunction Perovskite Solar Cells via One-Step Route. Phys. Chem. Chem. Phys. 2016, 18, 2625426261.

(26) Hou, X.; Hu, Y.; Liu, H.; Mei, A.; Li, X.; Duan, M.; Zhang, G.; Rong, Y.; Han, H. Effect of Guanidinium on Mesoscopic Perovskite Solar Cells. J. Mater. Chem. A 2017, 5, 73-78.

(27) Lee, H.; Kim, A.; Kwon, H.-C.; Yang, W.; Oh, Y.; Lee, D.; Moon, J. Retarding Crystallization during Facile Single Coating of NaCl-Incorporated Precursor Solution for Efficient Large-Area Uniform Perovskite Solar Cells. ACS Appl. Mater. Interfaces 2016, 8, 29419-29426.

(28) Marco, N. De; Zhou, H.; Chen, Q.; Sun, P.; Liu, Z.; Meng, L.; Yao, E. P.; Liu, Y.; Schiffer, A.; Yang, Y. Guanidinium: A Route to Enhanced Carrier Lifetime and Open-Circuit Voltage in Hybrid Perovskite Solar Cells. Nano Lett. 2016, 16, 1009-1016.

(29) Watthage, S. C.; Song, Z.; Shrestha, N.; Phillips, A. B.; Liyanage, G. K.; Roland, P. J.; Ellingson, R. J.; Heben, M. J. Enhanced Grain Size, Photoluminescence, and Photoconversion Efficiency with Cadmium Addition during the Two-Step Growth of $\mathrm{CH}_{3} \mathrm{NH}_{3} \mathrm{PbI}_{3}$. ACS Appl. Mater. Interfaces 2017, 9, 2334-2341.

(30) Ling, L.; Yuan, S.; Wang, P.; Zhang, H.; Tu, L.; Wang, J.; Zhan, Y.; Zheng, L. Precisely Controlled Hydration Water for Performance Improvement of Organic-Inorganic Perovskite Solar Cells. Adv. Funct. Mater. 2016, 26, 5028-5034.

(31) Jeon, Y.-J.; Lee, S.; Kang, R.; Kim, J.-E.; Yeo, J.-S.; Lee, S.-H.; Kim, S.-S.; Yun, J.-M.; Kim, D.-Y. Planar Heterojunction Perovskite Solar Cells with Superior Reproducibility. Sci. Rep. 2015, 4, 6953.

(32) Lv, M.; Dong, X.; Fang, X.; Lin, B.; Zhang, S.; Ding, J.; Yuan, N. A Promising Alternative Solvent of Perovskite to Induce Rapid Crystallization for High-Efficiency Photovoltaic Devices. RSC Adv. 2015, 5, 20521-20529.

(33) Yan, X.; Yang, X.; Wang, R.; Li, H.; Sheng, C. Effect on the Morphology and Optical Properties of $\mathrm{CH}_{3} \mathrm{NH}_{3} \mathrm{PbI}_{3}$ with Additive of $\mathrm{NH}_{4}$ Cl. Opt. Mater. 2017, 64, 461-467.

(34) Chen, C.-C.; Hong, Z.; Li, G.; Chen, Q.; Zhou, H.; Yang, Y. One-Step, Low-Temperature Deposited Perovskite Solar Cell Utilizing Small Molecule Additive. J. Photonics Energy 2015, 5, 057405.

(35) Chen, Y.; Zhao, Y.; Liang, Z. Nonvolatile Chlorinated Additives Adversely Influence $\mathrm{CH}_{3} \mathrm{NH}_{3} \mathrm{PbI}_{3}$ Based Planar Solar Cells. J. Mater. Chem. A 2015, 3, 9137-9140.

(36) Matsui, T.; Seo, J.; Saliba, M.; Zakeeruddin, S. M.; Grätzel, M. Room-Temperature Formation of Highly Crystalline Multication Perovskites for Efficient, Low-Cost Solar Cells. Adv. Mater. 2017, 29, 1606258.

(37) Bae, S.; Han, S. J.; Shin, T. J.; Jo, W. H. Two Different Mechanisms of $\mathrm{CH}_{3} \mathrm{NH}_{3} \mathrm{PbI}_{3}$ Film Formation in One-Step Deposition and Its Effect on Photovoltaic Properties of OPV-Type Perovskite Solar Cells. J. Mater. Chem. A 2015, 3, 23964-23972.

(38) Im, J.-H.; Jang, I.-H.; Pellet, N.; Grätzel, M.; Park, N.-G. Growth of $\mathrm{CH}_{3} \mathrm{NH}_{3} \mathrm{PbI}_{3}$ Cuboids with Controlled Size for High-Efficiency Perovskite Solar Cells. Nat. Nanotechnol. 2014, 9, 927-932.

(39) Shao, Y.; Xiao, Z.; Bi, C.; Yuan, Y.; Huang, J. Origin and Elimination of Photocurrent Hysteresis by Fullerene Passivation in $\mathrm{CH}_{3} \mathrm{NH}_{3} \mathrm{PbI}_{3}$ Planar Heterojunction Solar Cells. Nat. Commun. 2014, 5, 5784 .

(40) Lu, H.; Zhang, H.; Yuan, S.; Wang, J.; Zhan, Y.; Zheng, L. An Optical Dynamic Study of $\mathrm{MAPbBr}_{3}$ Single Crystals Passivated with $\mathrm{MAPbCl}_{3} / \mathrm{I}_{3}-\mathrm{MAPbBr}_{3}$ Heterojunctions. Phys. Chem. Chem. Phys. 2017, 19, 4516-4521. 